\title{
Flexing, Code Switching, and Leadership
}

"THE ABILITY TO 'FLEX' IS CRITICAL," SAYS LEADERSHIP STRATEGIST JANE HYUN

By Rhea Wessel

In the new book Flex: The New Playbook for Managing across Differences, co-authors Jane Hyun and Audrey S. Lee analyze the effectiveness of leaders who have the ability to "think differently." Hyun (a leadership strategist, executive coach, and author) shared some of her insights at the recent CFA Institute Annual Conference in Frankfurt. Previously a vice president of human resources and talent at J.P. Morgan and director of recruiting

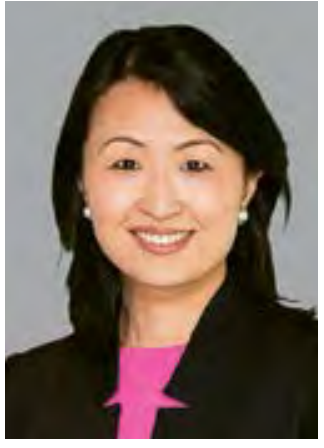

Jane Hyun at Deloitte \& Touche, Hyun draws on her experience to offer guidance for investment professionals trying to advance in modern firms. Following her presentation at the annual conference, she expanded on her views in an interview with CFA Institute Magazine.

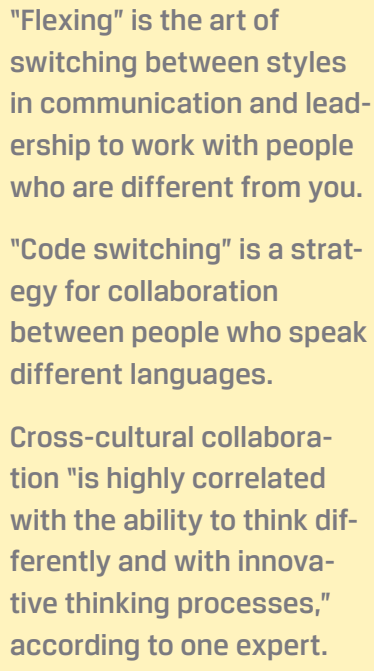

Cross-cultural collaboration "is highly correlated with the ability to think differently and with innovative thinking processes," according to one expert.

\section{What is "flexing," and why should investment professionals use the technique?}

"Flexing" is the art of switching between styles in communication and leadership to more effectively work with people who are different from you. And "different" is a very broad term. It could be culturally different, generationally different, or even across the gender divide. This is the art of flex.

At any stage in his or her development, an investment professional can use the strategy. As a new employee full of enthusiasm and with a new set of skills, you are ready to contribute. But you'll need to understand the culture of the organization. You'll need to understand who the leaders are and the feel of how things get done. The ability to flex is critical to getting the understanding you need to succeed in your job.

As you grow as a manager, have your own team, start to bring in clients, and work across borders, you'll have the opportunity to flex across these worlds, too. Ask yourself, "How will I flex [for] new customers? How will I flex [for] new team members, especially if they're younger and have different motivations and communication styles from me?"
There are many areas in which CFA Institute members can flex.

\section{What are your three strategies for stronger communication, and how do they work?}

The strategies help you consider where the other person is coming from and solve problems collaboratively in a way that is non-confrontational. I know the case of a senior manager who took a junior manager to a meeting with a client. The junior manager promised the client that the team would meet a tight deadline. The senior manager knew it wasn't possible, but the junior manager, being of Indian heritage, was operating under the cultural understanding that you don't say no to someone in a position of authority, such as a client.

This is where the senior manager can use the three strategies. Instead of getting worked up about the unrealistic deadline, she should first ask herself, "What is the junior manager thinking?" Next, "How can I best connect?" Here, the idea is to consider in advance how to interact to correct the situation in a way that is positive. Third (and finally), the senior manager must ask herself, "How do I put myself in the other person's shoes?" Being mindful and thoughtful before a face-to-face interaction is something rarely found in today's warp-speed business environment. When working with someone different from you, it is critical to take a step back before engaging.

What is "code switching," and how do you use it at work? Code switching actually stems from language. When I say code switching, I mean coming up with a third language to more effectively work with someone who is speaking a different language from your own. When you are culturally flexing and adapting, it's like speaking Spanglish, a mixture of Spanish and English. You have recognized that everyone brings their unique perspective to every encounter; therefore, you try to find a new way of engagement by understanding the other person's perspective.

I think it's important for a manager or leader who is in a position of power to do the flexing and code switching first [in order] to reach out to more junior people. It doesn't always work this way. At some organizations that are hierarchical, the approach is to say, "Well, you're new; it's your job to figure out how things work. We've been here for years."

In my newest book with Audrey S. Lee, Flex: The New Playbook for Managing across Differences, we challenge people to flex first if they understand the rules of the game and know how things work, to help people understand those unwritten rules. 
You are of Korean heritage, and you have studied communication styles in China. How has this perspective influenced your concept of flexing?

China is a very collectivist culture. People are uncomfortable tooting their own horns, and companies hiring in China need to understand this. Let's say you need a Chinese team to run the operations behind your fund. What can you do to make sure you hire the right people?

I believe each group can flex in this situation. The Chinese candidate can be more in your face and direct and say, "Our team pulled together and accomplished ABC" and "This is how I made it happen."

On the other side, the company doing the hiring can flex by understanding that the language of relationship building in China is [in] spending time with each other. Instead of going in and hiring someone after the first interview, someone who is astute about hiring in China would take more time.

\section{What is your thinking behind the idea of "comfort with ambiguity," one of six traits you list that belong to a "fluent leader"?}

When you have ambiguous situations, when you see that communication can be both direct and indirect, some people get stuck in one mode or the other. They say, "It's only good to be direct." But as you open up your mind to different cultural perspectives, you automatically are thinking about new realms and ways of doing things. Multicultural thinking is highly correlated with the ability to think differently and with innovative thinking processes. Leaders we studied who were fluent had an insatiable curiosity about those who were different from them. When I look at success stories, I see leaders who think differently as the ones who were able to impact change at the organizational level.

In your presentation at the annual conference, you discussed showing emotion at work. How do you know the right approach?

Each human being is expressive in different ways, and this has cultural roots, such as the amount of emotion we are allowed to show. There are some cultural groups that encourage people to express emotion at work. In cultures that value expression, they say, "You have to be passionate. You have to show your passion in the way you talk and communicate what you know."

If you grew up in a restrained culture, it's valued to be more matter of fact. You need to understand both sides. If you're restrained, study up on how to flex so that you can show more emotion, especially if you're kicking off a new project. The way you show emotion may not look as extreme as a colleague who is more comfortable with that approach, but your ability to adapt can make a difference. It's about understanding the cultural group you're in but also what you bring to the table [and] about having an awareness of who you are naturally and knowing how to adapt to the situation.

Rhea Wessel is a freelance journalist in Frankfurt.

\section{KEEP GOING}

"Cultural Travelers: Global careers cross boundaries greater than geography," CFA Institute Magazine (May/June 2015) [www.cfapubs.org] 